\title{
Prevalence and correlates of obesity in insulin dependent diabetic patients
}

\author{
E Bognetti, P Macellaro, D Novelli, F Meschi, F Ciralli, G Chiumello
}

\begin{abstract}
The prevalence of obesity, according to sex and pubertal stage, and the correlations between obesity and metabolic data were investigated in 286 diabetic patients (164 boys, 122 girls) with mean (SD) age $15 \cdot 3(3 \cdot 2)$ years and mean (SD) duration of diabetes $7 \cdot 5(4 \cdot 1)$ years. Prevalence of obesity according to the body mass index (BMI) criteria was 6.3\%. Girls were more often obese than boys but the prevalence approached statistical significance only for the BMI criteria, at $9.8 \%$ v $3.7 \%$ $\left(\chi^{2}=3 \cdot 5 ; \mathbf{p}=0 \cdot 06\right) ;$ obesity was independent of pubertal stage. Distribution of BMI values of diabetic girls was skewed towards the high centiles of the INSERM tables: <25th centile, 8.6\%; 25th-50th centile, $17 \cdot 3 \%$; 50th-75th centile, $25 \cdot 9 \%$; $>75$ th centile, $48 \cdot 2 \% \quad\left(\chi^{2}=19 \cdot 17\right.$, $\mathbf{p}<0 \cdot 0005)$. BMI values of diabetic boys were homogeneously distributed. Age, duration of diabetes, insulin requirement, daily number of insulin injections, and metabolic control (HbA1c) were comparable in obese and non-obese diabetic patients. Moreover metabolic control and insulin requirements were comparable between diabetic patients with BMI above and below the 50th centile of the INSERM tables after matching for sex. In conclusion the prevalence of obesity in diabetic children and adolescents is quite similar to the prevalence reported in their nondiabetic peers. Obesity and BMI excess correlate with female gender but are independent of insulin requirement and metabolic control.
\end{abstract}

(Arch Dis Child 1995; 73: 239-242)

Keywords: type I diabetes mellitus, obesity, adolescence, body mass index.

Obesity is not generally thought to be a typical feature of type I (insulin dependent) diabetes mellitus. However, in the United Kingdom, a similar prevalence of obesity was reported in diabetic and non-diabetic children. ${ }^{1}$ So far no other studies have been carried out on this subject.

There is interest in childhood obesity because of its increasing prevalence ${ }^{2-6}$ and because of the observation that a large proportion of obese children become obese adults. ${ }^{7-9}$ Moreover obesity in childhood has been associated with many other conditions such as hypertension, ${ }^{10}$ respiratory disease, ${ }^{11}$ cardiovascular disease risk, ${ }^{12}$ and psychological problems. ${ }^{13}$$$
\text { problems. }{ }^{13}
$$

Diet is a common tool in the management of diabetes mellitus as well as of obesity, and poor dietary compliance is often associated with poor metabolic control in diabetic patients and with unsuccessful body weight reduction in obese patients.

The aims of our study were to assess the prevalence of obesity in diabetic patients according to sex and pubertal stage, and to examine the correlations between obesity and metabolic control.

\section{Methods}

During a cross sectional study performed on a clinic based population, we consecutively enrolled 286 diabetic patients (164 boys, 122 girls) aged five years or older, who attended our paediatric outpatient clinic and had been diabetic for more than two years. Their mean age was 15.3 (SD 3.2) years and the mean duration of diabetes was $7 \cdot 5(4 \cdot 1)$ years. All the subjects were receiving short and long acting insulin and were regularly seen at our outpatient clinic.

Height was measured by Harpenden stadiometer (Holtain, UK) and weight was recorded without shoes or outer clothing. Puberty was assessed clinically according to Tanner and Whitehouse ${ }^{14}{ }^{15}$ : stage 1 , prepubertal; stage 2-4, pubescent; stage 5, pubertal. According to this pubertal stage assessment, we enrolled 30 prepubertal patients with mean age 10.4 $(1.4)$ years; 96 pubescent patients with mean age $13.4(1 \cdot 7)$ years, and 160 pubertal patients with mean age $17 \cdot 5(2 \cdot 3)$ years.

The subjects were regarded as obese when their body mass index (BMI), calculated by dividing weight $(\mathrm{kg})$ by height squared $\left(\mathrm{kg} / \mathrm{m}^{2}\right)$, was above the 97th centile of the INSERM table, according to age and sex. ${ }^{16}$ To compare the prevalence of obesity in our cohort of patients with previously published data, we calculated the predicted weight for height $(\mathrm{W} / \mathrm{H})$ and identified obese patients as those in whom $\mathrm{W} / \mathrm{H}$ was greater than $120 \%$. Since reference growth tables for the Italian population are not available, Tanner's growth tables were used to calculate the $\mathrm{W} / \mathrm{H}$ of each patient. ${ }^{17}$

Glycated haemoglobin (HbA1c) was assessed in the week before the visit by different laboratories; to standardise these results we used the percentage of $\mathrm{HbAlc}$ variation above the normal upper limit for each of the laboratories $(\mathrm{HbA1c} \Delta)$.

Daily insulin requirement was expressed as units/kg body weight.

Data are given as mean(SD). Comparisons between groups were performed by the Student $t$ test and $\chi^{2}$ test. Two tailed $\mathrm{p}$ values
Dr Emilio Bognetti, Clinica Pediatrica, Ospedale San Raffaele, Via Olgettina 60 Milan, Italy

Accepted 24 April 1995 


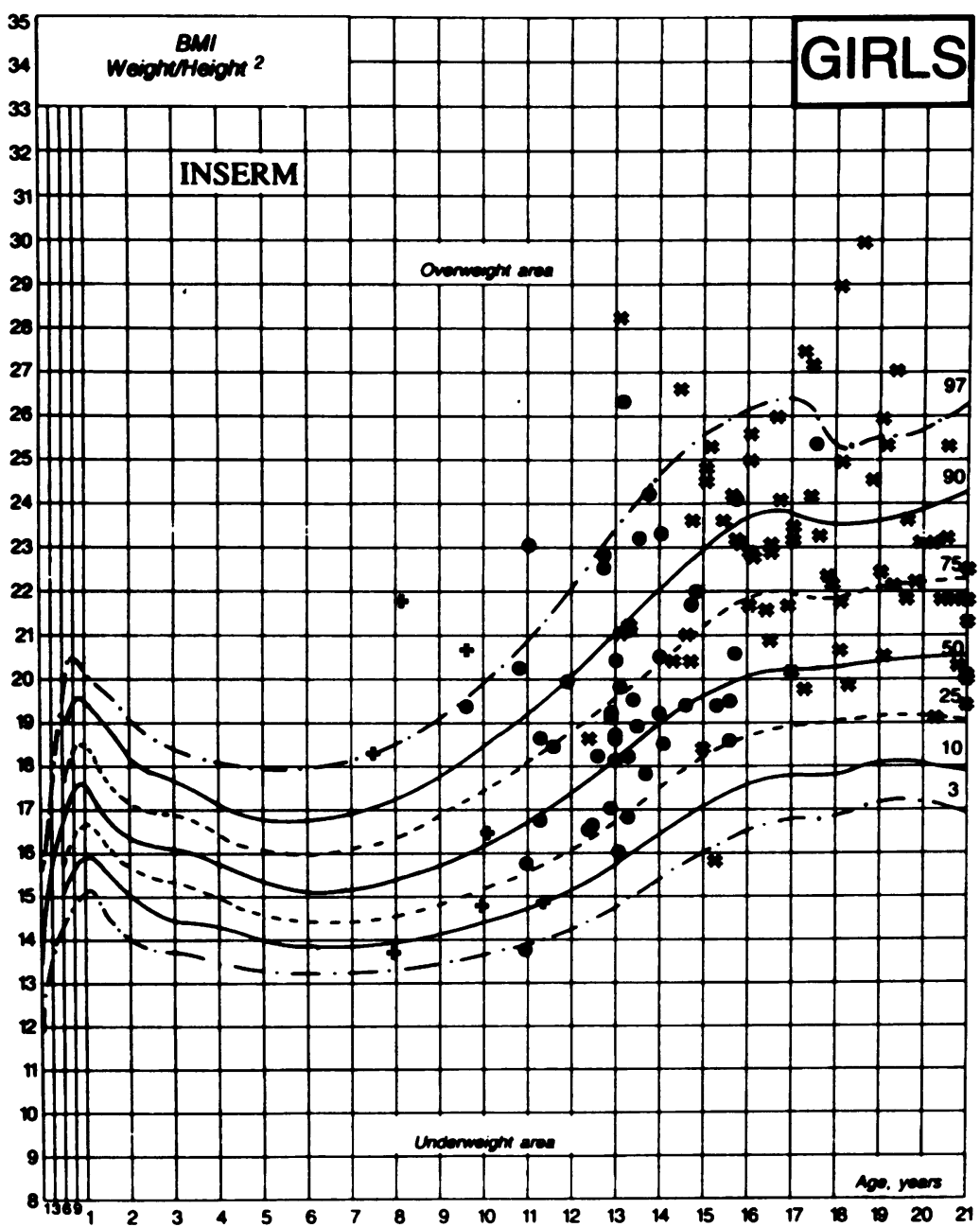

Figure 1 BMI value distribution in diabetic girls according to age and pubertal stage ( $+=P 1 ; 0=P 2-4 ; \#=P 5)$.
Age, duration of diabetes, insulin requirement, daily number of insulin injections, and metabolic control (HbAlc $\Delta$ ) were comparable in obese and non-obese diabetic patients identified according to BMI criteria (table 2).

HbAlc $\Delta$ was comparable between patients with BMI values above and below the 50 th centile matched for sex: girls, $51.7(32.2) \% v$ $53 \cdot 8(33 \cdot 4) \%$; boys, $41 \cdot 1(30 \cdot 2) \%$ v $48 \cdot 6$ $(30 \cdot 6) \%$.

Insulin requirement was comparable between patients with BMI values above and below the 50th centile matched for sex: girls, $0.82(0.25) v 0.88(0.27) \mathrm{U} / \mathrm{kg}$; boys, 0.86 $(0.23) v 0.84(0.22) \mathrm{U} / \mathrm{kg}$.

\section{Discussion}

In our study we have analysed the prevalence of obesity in a cohort of diabetic patients randomly enrolled from a clinic based population. Bias may arise from epidemiological studies performed on a clinic based population, particularly when such populations are not representative of the general diabetic population. Our outpatient diabetic clinic follows more than 400 diabetic children and adolescents living in an area with about 1.5 million inhabitants below 18 years of age and a prevalence of insulin dependent diabetes mellitus of around 90/100 000 inhabitants. ${ }^{18}$ According to these data, the diabetic population followed by our department is too large to be considered a selected cohort.

In our study the prevalence of obesity was quite comparable with the prevalence reported in the children's non-diabetic Italian peers ${ }^{2-6}$ (table 3 ) and with the prevalence reported by Abusrewil and Savage in the English study, ${ }^{1}$ suggesting that obesity in type I diabetic children is frequently observed and is independent of regional dietary habits, at least with regard to Italian and English diets.

The criterion most frequently used to detect obesity is the predicted weight for height (W/H) according to the Tanner growth tables ${ }^{18}$ but recently a method based on BMI adjusted for age and sex has been suggested to avoid the interference of age and height changes on weight gain. This method, based on centile distribution tables (INSERM tables), identifies obese subjects when the BMI is above the 97 th centile. ${ }^{16}$ The INSERM tables were developed in France and no similar tables are available for the Italian population. However the similarity between the French and Italian populations permits their use in our study. The same problem arises with the Tanner tables, developed on the English

Table 1 Distribution of body mass index (BMI) values of diabetic boys and diabetic girls according to the centiles of the INSERM tables. Data are given as absolute numbers and percentage (\%). Expected frequency for each centile is $25 \%$

\begin{tabular}{lll}
\hline Centiles & Diabetic boys & Diabetic girls \\
\hline$<25$ & $32(19 \cdot 5)$ & $11(9 \cdot 0)$ \\
$25-50$ & $35(21 \cdot 3)$ & $21(17 \cdot 2)$ \\
$50-75$ & $48(29 \cdot 3)$ & $29(23 \cdot 8)$ \\
$>75$ & $49(29 \cdot 9)$ & $61(50 \cdot 0)$ \\
\hline
\end{tabular}

${ }^{\star} \chi^{2}: 19 \cdot 17(\mathrm{p}<0 \cdot 0005)$. latter: 15 of 18 patients obese by the BMI criteria were also obese by the $\mathrm{W} / \mathrm{H}$ criteria $(83.3 \%) ; 14$ out of 31 patients obese by the W/H criteria were also obese by the BMI criteria $(45 \cdot 2 \%)$. 


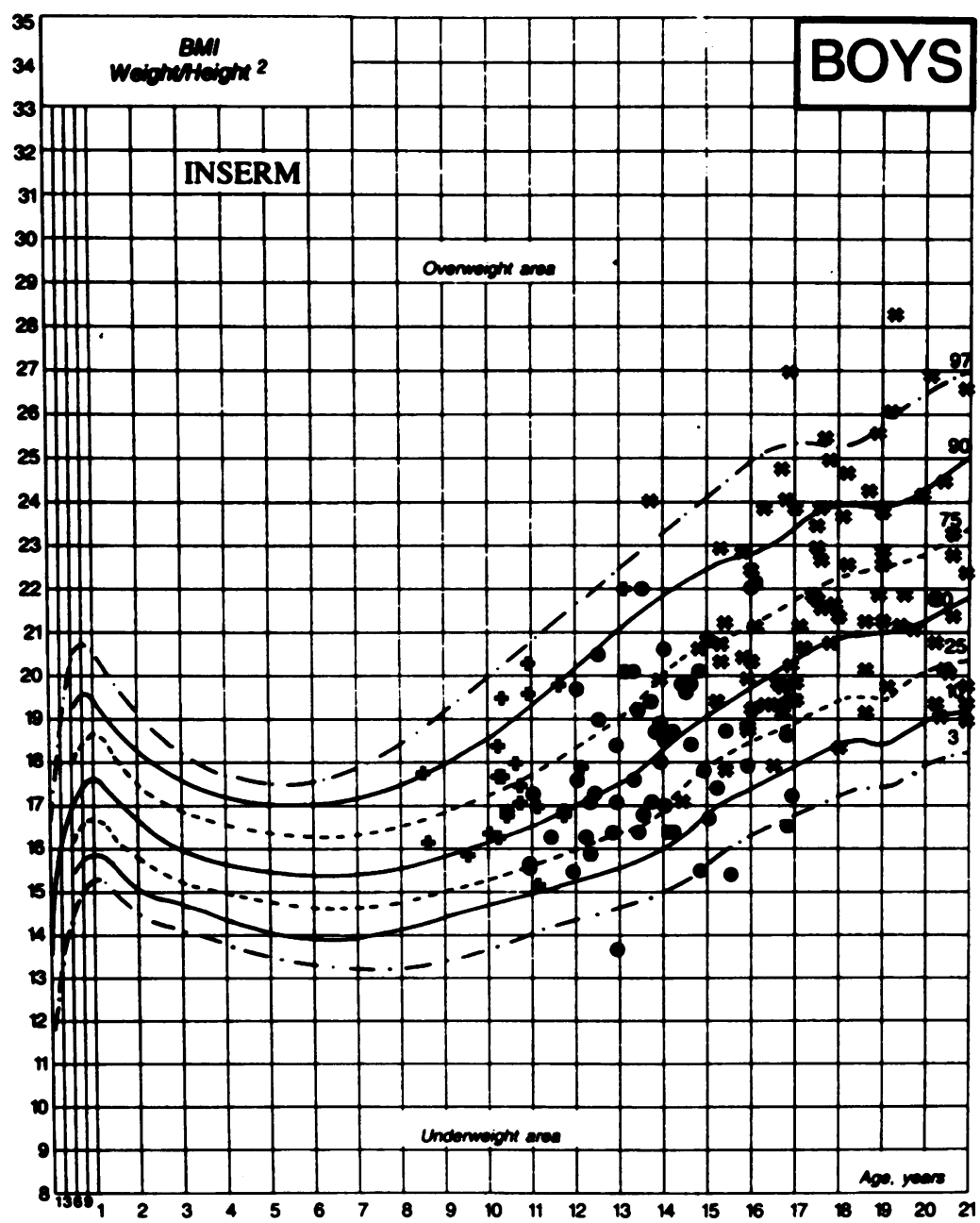

Figure 2 BMI value distribution in diabetic boys according to age and pubertal stage ( $t=P 1 ; O=P 2-4 ; \#=P 5)$.

population but widely used in many countries and recently accepted by an Italian Consensus Conference ${ }^{19}$ as the reference tables for assessing predicted weight for height.

Girls were more frequently obese than boys, but the prevalence only approached significance $(p=0.06)$ for the BMI criteria; the distribution of BMI values was skewed towards the high centiles of INSERM tables for girls but not for boys. This observation is very different

Table 2 Clinical and metabolic data of obese and non-obese diabetic patients

\begin{tabular}{llc}
\hline & Obese & Not obese \\
\hline Number (boys/girls) & $18(6 / 12)$ & $268(158 / 110)$ \\
Age, years (SD) & $15 \cdot 6(3 \cdot 7)$ & $15 \cdot 3(3 \cdot 2)$ \\
Duration of diabetes, years (SD) & $7 \cdot 6(3 \cdot 7)$ & $7 \cdot 4(4 \cdot 1)$ \\
Insulin requirement, U/kg body weight (SD) & $0 \cdot 84(0 \cdot 20)$ & $0 \cdot 85(0 \cdot 24)$ \\
Two insulin injections/day (\%, No) & $50(9)$ & $57(147)$ \\
Three insulin injections/day (\%, No) & $50(9)$ & $43(111)$ \\
HbAlc $\Delta, \%$ (SD) & $47 \cdot 9(21 \cdot 1)$ & $47 \cdot 7(32 \cdot 2)$ \\
\hline
\end{tabular}

HbAlc $\Delta=$ percentage of glycated haemoglobin values above upper limit for laboratory reference values.

Table 3 Prevalence (\%) of obesity in children (boys and girls) as reported by other Italian (I) and English (UK) studies. Obesity was assessed by the predicted weight for height method

\begin{tabular}{lllllll}
\hline & Area & Year & Age & Boys and girls & Boys & Girls \\
\hline Abusrewil $^{1}$ & Bristol (UK) & 1989 & $5-22$ & $9 \%$ & - & - \\
Zoppi $^{5}$ & Verona (I) & 1989 & $6-18$ & $12 \%$ & $13 \%$ & $12 \%$ \\
Ceratti $^{3}$ & Milan (I) & 1990 & $6-18$ & $15 \%$ & $15 \%$ & $14 \%$ \\
Present study & Milan (I) & 1994 & $7-23$ & $11 \%$ & $\mathbf{8 \%}$ & $15 \%$ \\
\hline
\end{tabular}

from the data reported in Italian non-diabetic population, which is characterised by a higher prevalence of obesity in boys than in girls. ${ }^{23}$

In our study, designed to assess the prevalence of obesity, we have not analysed the possible mechanisms involved in excess weight gain. However, resting metabolic rate has not been reported to be modified by diabetes mellitus per se, ${ }^{20}$ while abnormal dietary habits ${ }^{21}{ }^{22}$.have been reported more frequently in girls than in boys with diabetes mellitus.

The prevalence of obesity in our cohort was independent of pubertal stage, while in nondiabetic subjects it has been shown to increase significantly with age. ${ }^{2}$ The comparable prevalence of obesity between the younger prepubertal diabetic patients and the older pubescent and pubertal patients in our study could be related to the dietary habits of the younger patients. In young diabetic children frequent or excessive snacks are often used to prevent hypoglycaemic episodes, and this could in part explain an excessive weight gain.

According to our data the prevalence of obesity was lower using BMI criteria than using W/H criteria, and concordance for obesity between BMI and $\mathrm{W} / \mathrm{H}$ was greater in patients identified by the BMI criteria. Therefore we used BMI to identify obesity in the subsequent comparison of the clinical and metabolic variables between obese and nonobese diabetic patients.

In diabetic patients excessive energy intake can easily cause excess weight gain accompanied by metabolic derangement, but weight gain has also been reported during improvement of metabolic control. ${ }^{23} \mathrm{We}$ did not observe any relation between obesity or BMI values and glycated haemoglobin, insulin requirement as units/kg body weight, or daily insulin schedule, as previously reported by Abusrewil and Savage in the English study. ${ }^{1}$ These data suggest that in obese diabetic patients, increases in insulin dosage related to body weight gain may have prevented severe metabolic derangement, but probably assisted in maintaining the excessive body weight.

In conclusion obesity in young diabetic patients, particularly in girls, is not a rare observation. Excessive weight gain should be prevented to avoid the complications associated with obesity and the difficulties relating to its treatment.

1 Abusrewil SS, Savage DCL. Obesity and diabetic control. Arch Dis Child 1989; 64: 1313-5

2 Maffeis C, Schutz Y, Piccoli R, Gonfiantini E, Pinelli Prevalence of obesity in children in north-east Italy. Int $\dot{f}$ Obesity 1993; 17: 287-94.

3 Ceratti F, Garavaglia M, Piatti L, et al. Screening dell obesitê nella popolazione scolastica della zona 20 di Milano ed intervento di educazione alimentare. Epidemiol Prevenzione 1990; 45: 1-6.

4 Giovannini M, Galluzzo G, Scaglioni S, et al. Anthropometric data and dietary habits of a paediatric population in Milan. Riv Ital Pediatr 1986; 12: 533-40.

5 Zoppi G, Bressan F. Obesity in pediatrics: analysis of some definitions and determination of their limits on Italian standards. Riv Ital Pediatr 1989; 16: 139-43.

6 Gortmaker SL, Dietz WH, Sobol AM, Wehler CA Increasing pediatric obesity in the United States. $A m \mathcal{F} D i$ Child 1987; 141: 535-40.

7 Garn SM, Lavelle M. Two decade follow-up of fatness in early childhood. Am f Dis Child 1985; 139: 181-5.

8 Braddon FEM, Rodgers B, Wadsworth MEJ, Davies JMC. 1986; 293: 299-303. 
9 Mossberg HO. Forty year follow-up of overweight children. Lancet 1989; ii: 491-4.

10 Johnson AL, Cornoni JC, Cassel JC, Tyroler HA, Heyden pressure behavior in young adults. Am $\mathcal{f}$ Cardiol 1975; 35: 523-30.

11 Inselman LS, Wapnir RA, Spencer H. Obesity induced hyperplastic lung growth. Am Rev Respir Dis 1987; 135: 613-6.

12 Smoak CG, Burke GL, Webber LS, Harsha DW, Srinivasan SR, Berenson GS. Relation of obesity to Srinivasan SR, Berenson GS. Relation of obesity to and young adults (The Bogalusa Heart study). Am $\mathfrak{f}$ and young adults (The Bog
Epidemiol 1987; 125: 364-72.

13 Stunkard A, Burt V. Obesity and the body image: II. Age onset of disturbances in the body image. Am $\mathcal{f}$ Psychiatry 1967; 123: 1443-7.

14 Marshall W, Tanner J. Variation in the pattern of pubertal change in girls. Arch Dis Child 1969; 44: 291-303.

15 Marshall W, Tanner J. Variation in the pattern of pubertal change in boys. Arch Dis Child 1970; 45: 13-23.

16 Rolland-Cachera MF, Cole TJ, Sempé M, Tichet J, Rossignol C, Charraud A. Body mass index variations: centiles from birth to 87 years. Eur $\mathcal{f}$ Clin Nutr 1991; 45: 13-21.

17 Tanner J, Whitehouse RH. Clinical longitudinal standards for height, weight, height and weight velocity and stages of puberty. Arch Dis Child 1976; 51: 170.

18 Gallus G, Garancini P. Dati di epidemiologia sul diabete mellito in lombardia. Epidemiol Prevenzione 1991; 48: 55-8.

19 Crepaldi C, Belfiore F, Bosello O, et al. Consensus Conference Italiana: Sovrappeso, Obesitàe Salute (CCI S.O.S. '91). Ann Ital Med Intern 1991; 6: 359

20 Manzoni P, Davies PSW, Challoner J, Lucas A, Chiumello G. Body composition and energy metabolism in diabetic adolescent girls and effect of exercise trial. Horm Res 1994; 41: 2 .

21 Stancin T, Link DL, Reuter JM. Binge eating and purging in young women with IDDM. Diabetes Care 1989; 12: $601-3$.

22 Marcus MD, Wing RR. Eating disorders and diabetes. In: Holmes CS, ed. Neuropsychological and behavioral aspects of diabetes. New York: Springer Verlag, 1990: 122-9.

23 Haas K, Nue A, Petrig-Lenz M, Rauke MB. Obesity in diabetic children during puberty. It affects girls during late puberty. A retrospective study. Diabetes in the Young, 1992; Abstract issue: 28 . 